\title{
Analysis of inertia and scale effects on dynamic neck formation during tension of sheet steel
}

\author{
A. Rusinek ${ }^{\mathrm{a}, *}$, R. Zaera ${ }^{\mathrm{b}}$, J.R. Klepaczko ${ }^{\mathrm{a}}, \mathrm{R}$. Cheriguene ${ }^{\mathrm{a}}$ \\ ${ }^{a}$ Laboratory of Physics and Mechanics of Materials, UMR CNRS 75 54, University of Metz, Ile du Saulcy, 57045 Metz Cedex, France \\ ${ }^{\mathrm{b}}$ Department of Continuum Mechanics and Structural Analysis, University Carlos III of Madrid, Avda. de la Universidad 30, 28911 Leganés, Madrid, Spain
}

\begin{abstract}
It is well known that a specimen for impact testing must be optimized in terms of its dimensions. The main reason is to reduce strain gradients due to the effects of elastic plastic wave propagation. On the other hand, when a split Hopkinson bar in tension is applied, the net displacement of the specimen ends is very limited, usually from 2.0 to $3.0 \mathrm{~mm}$. Thus, to reach a maximum strain of 0.5 the specimen length must be reduced in dimensions from 4.0 to $6.0 \mathrm{~mm}$. Consequently, small diameters or lateral dimensions and lengths must be applied to assure one dimensional deformation. Such small lengths substantially perturb the determination of real material behavior. So the main motivation of this study was to perform a systematic analysis, numerical and analytical, to find differences in the behavior of short and long specimens loaded in impact tension. The finite element code ABAQUS/Explicit has been used to simulate several spec imen lengths from 10 to $40 \mathrm{~mm}$ submitted to impact velocities ranging from 10 to $100 \mathrm{~m} / \mathrm{s}$.
\end{abstract}

Keywords: Constitutive relation; Dynamic tension; Normalization; Plastic instability; Numerical simulations

\section{Thermoviscoplastic modeling}

To study the dynamic processes of plastic deformation in sheet metals, a well defined constitutive relation has earlier been proposed. Several processes of fast deformation have been previously studied by applying that relation: perforation [1], double shear by direct impact [2], the Taylor test and fast tension test [3]. With the constitutive relation, Eq. (1), the effect of temperature and strain rate on the flow stress can be studied and analyzed. It is clear that the adiabatic increase of temperature has a substantial effect on the flow stress and it induces a decrease in the ultimate tensile stress. In order to describe precisely the behavior of materials at high strain rates and temperatures, the equivalent stress $\sigma$ needs to be taken as the sum of two components $\sigma_{\mu}$ and $\sigma^{*}$ which are, respectively, the internal and the effective stress. The first component is directly related to

\footnotetext{
* Corresponding author. Tel.: +33 3873150 20; fax: +33 387315366 .

E mail address: rusinek@univ metz.fr (A. Rusinek).
}

the strain hardening of the material and the second defines the contribution due to the thermal activation (a combination of temperature and strain rate). The constitutive relation can be written in terms of equivalent scalar quantities:

$\sigma\left(\varepsilon^{\mathrm{p}}, \dot{\varepsilon}^{\mathrm{p}}, T\right)=\frac{E(T)}{E_{0}}\left[\sigma_{\mu}\left(\varepsilon^{\mathrm{p}}, \dot{\varepsilon}^{\mathrm{p}}, T\right)+\sigma^{*}\left(\dot{\varepsilon}^{\mathrm{p}}, T\right)\right]$,

where $\varepsilon^{\mathrm{p}}$ is the equivalent plastic strain, $T$ is the absolute temperature, $E_{0}$ is the Young's modulus at $T 0 \mathrm{~K}$ and $E(T)$ is the evolution of the modulus as a function of temperature. Eq. (1) is based to some extent on physical considerations [2]. The explicit expressions for both stress components are given below:

$\sigma_{\mu}\left(\varepsilon^{\mathrm{p}}, \dot{\varepsilon}^{\mathrm{p}}, T\right)=B\left(\dot{\varepsilon}^{\cdot \mathrm{p}}, T\right)\left(\varepsilon_{0}+\varepsilon^{\mathrm{p}}\right)^{n\left(\varepsilon^{\mathrm{p}}, T\right)}$,

where $B\left(\dot{\varepsilon}^{\mathrm{p}}, T\right)$ and $n\left(\dot{\varepsilon}^{\mathrm{p}}, T\right)$ are the modulus of plasticity and the strain hardening exponent, respectively. These quantities, defined by Eqs. (3) and (5), respectively, take into account the experimental observations that the strain hardening itself depends on temperature and strain rate. 


$$
\begin{aligned}
n\left(\dot{\varepsilon}^{\mathrm{p}}, T\right)= & \left\langle n_{0}\left(1-D_{2}\left(\frac{T}{T_{\mathrm{m}}}\right) \log \left(\frac{\dot{\varepsilon}^{\mathrm{p}}}{\dot{\varepsilon}_{\text {min }}}\right)\right)\right\rangle \text { with } \\
& \dot{\varepsilon}_{\text {min }} \leqslant \dot{\varepsilon}^{\mathrm{p}} \leqslant \dot{\varepsilon}_{\max },
\end{aligned}
$$

where $n_{0}$ and $D_{2}$ are material constants, $T_{\mathrm{m}}$ is the melting point, $\dot{\varepsilon}_{\min }$ is the minimum strain rate which defines the quasi-static stress strain relation, $\dot{\varepsilon}_{\max }$ is the maximum limit of strain rate. where $\langle\bullet\rangle$ are the MacCauley brackets:

$$
\langle\bullet\rangle= \begin{cases}\bullet & \text { if } \bullet \geqslant 0, \\ 0 & \text { if } \bullet<0\end{cases}
$$

such that negative values of the hardening exponent are not allowed.

For the ES mild steel (C: $0.03 \%$, S: $0.011 \%$, Mn: $0.203 \%$, Al: $0.054 \%$, Cr: $0.041 \%$, Ni: $0.018 \%$ ) $[1,2]$ analyzed in this paper, the strain-hardening exponent $n$ substantially changes with strain rate and temperature, particularly in the adiabatic conditions [2]. This mild steel is used for deep drawing applications due to its large ductility. Moreover, the effective strain rate $\dot{\varepsilon}^{\mathrm{p}}$, which corresponds to the complete transition into adiabatic conditions of deformation is estimated as $\dot{\varepsilon}^{\mathrm{p}} \approx 10 \mathrm{~s}^{-1}$. For strain rates higher or equal to $10^{2} \mathrm{~s}^{1}$, a significant temperature increase $\Delta T$ is observed with plastic deformation and at the same time an intensification of the thermal softening of the material occurs. The process of plastic deformation is then coupled with temperature as will be shown later. The formula for $B\left(\dot{\varepsilon}^{\mathrm{p}}, T\right)$ is a function of the homologous temperature modified by strain rate [3]:

$$
\begin{aligned}
B\left(\dot{\varepsilon}^{\mathrm{p}}, T\right)= & \left\langle B_{0}\left(\left(\frac{T}{T_{\mathrm{m}}}\right) \log \left(\frac{\dot{\varepsilon}_{\max }}{\dot{\varepsilon}^{\mathrm{p}}}\right)\right)^{v}\right\rangle \text { with } \\
& \dot{\varepsilon}_{\text {min }} \leqslant \dot{\varepsilon}^{\mathrm{p}} \leqslant \dot{\varepsilon}_{\max },
\end{aligned}
$$

where $B_{0}$ is the material constant and $v$ is the temperature sensitivity (usually negative).

The explicit form of the effective stress $\sigma^{*}$, given by Eq. (6), is similar to the Arrhenius relation which describes the kinetics of thermally activated processes:

$$
\begin{aligned}
\sigma^{*}\left(\dot{\varepsilon}^{\mathrm{p}}, T\right)= & \left\langle\sigma_{0}^{*}\left(1-D_{1}\left(\frac{T}{T_{\mathrm{m}}}\right) \log \frac{\dot{\varepsilon}_{\max }}{\dot{\varepsilon}^{\mathrm{p}}}\right)^{1 / m}\right\rangle \text { with } \\
& \dot{\varepsilon}_{\min } \leqslant \dot{\varepsilon}^{\mathrm{p}} \leqslant \dot{\varepsilon}_{\max },
\end{aligned}
$$

where $\sigma_{0}^{*}$ is the effective stress at $T \quad 0 \mathrm{~K}, D_{1}$ is the material constant and $m^{*} \quad 1 / m$ is the coefficient characterizing the temperature and strain rate sensitivity. In adiabatic conditions the quantities that are functions of temperature are coupled via Eq. (7), which gives the increment of temperature $\Delta T_{\text {adiabatic }}$ due to the plastic work converted into heat [30].

The adiabatic increase of temperature triggers the thermal softening phenomenon and reduces the rate of strain hardening

$$
\begin{aligned}
T_{\text {adiabatic }} & =T_{0}+\Delta T_{\text {adiabatic }}, \\
T_{\text {adiabatic }} & =T_{0}+\frac{\beta}{\rho C} \int_{\varepsilon_{\mathrm{e}}}^{\varepsilon^{\mathrm{p}}} \sigma\left(\xi, \dot{\varepsilon}^{\mathrm{p}}, T\right) \mathrm{d} \xi,
\end{aligned}
$$

where $\beta$ is the Taylor Quinney coefficient of plastic work converted into heat, $\rho$ is the density of material and $C$ is the specific heat at constant pressure. In our case $C$ is constant but generally it is a function of temperature [28,29].

The material constants used to describe the thermoviscoplastic behavior of ES steel are given in [1 4]. It is commonly observed that an increase of strain rate causes an increase of the yield and flow stress. The logarithmic rate sensitivity $m$ is very important in modeling of the thermoviscoplastic behavior of materials. This parameter, defined by the following relation, Eq. (8), is close to $m \approx 0.02$ for the sheet of mild steel at low strain rate for room temperature

$m(T)=\left.\frac{\partial \log \sigma}{\partial \log \varepsilon^{\mathrm{p}}}\right|_{\varepsilon^{\mathrm{p}}, T} \quad$ with $m \geqslant 0$.

The experimental results reported in [4] have permitted the determination of the logarithmic strain rate sensitivity for ES steel. For the range of low strain rates $10^{-4} \leqslant$ $\dot{\varepsilon}^{\mathrm{p}} \leqslant 10^{-1} \mathrm{~s}^{-1}$, the strain rate sensitivity is $m \quad 0.023$ and increases to $m 0.05$ for the range of high strain rates $1 \leqslant \dot{\varepsilon}^{\mathrm{p}} \leqslant 10^{3} \mathrm{~s}^{-1}$ for strain level $\varepsilon^{\mathrm{p}}=0.1$. However, at larger plastic strain a decrease of the strain rate sensitivity is induced by the thermal softening of the material; this effect is more important when the strain rate increases. It can be stated that the apparent strain rate sensitivity which is coupled with temperature strongly depends on the plastic work accumulated during plastic deformation and converted into heat. In general the thermal softening of the stress causes this phenomenon. The value of the apparent strain rate sensitivity can change at high strain rates with the specimen geometry as will be shown later after the numerical analysis, more precisely for a short specimen. If the process of thermal softening resulting from the coupling $\dot{\varepsilon}^{\mathrm{p}}-T$ is not well defined, the process of plastic deformation cannot be studied correctly. In our case, the strong coupling $\dot{\varepsilon}^{\mathrm{p}}-T$ inducing a thermal softening of the material is partly caused by variation of the strain hardening exponent $n\left(\dot{\varepsilon}^{\mathrm{p}}, T\right)$, Eq. (3). When temperature or strain rate increases then $n\left(\dot{\varepsilon}^{\mathrm{p}}, T\right) \rightarrow 0$ which is commonly observed in dynamic tests.

Several constitutive equations have been proposed in the past. Those proposed by Cowper and Symonds [5] and Johnson and Cook [6] are empirical, and in that due to Zhao [7], an extension of the Tanimura formulation [47], temperature effects are not included. Zerilli and Armstrong [9] proposed a constitutive relation coupled with temperature and with some background of materials science. Next, a comparison between some of these constitutive relations for sheet steel ES is performed, Fig. 1. Apparently, a relatively good agreement with experiment for small strains and constant temperature is found for the relation proposed by Zhao. A simple reason for this agreement is the additive form of the relation where an increase of strain rate causes a translation of strain stress curve toward higher stresses. The disadvantage of all phenomenological relations formulated at constant temperature is the very limited range of applications of all numerical simulations at high 


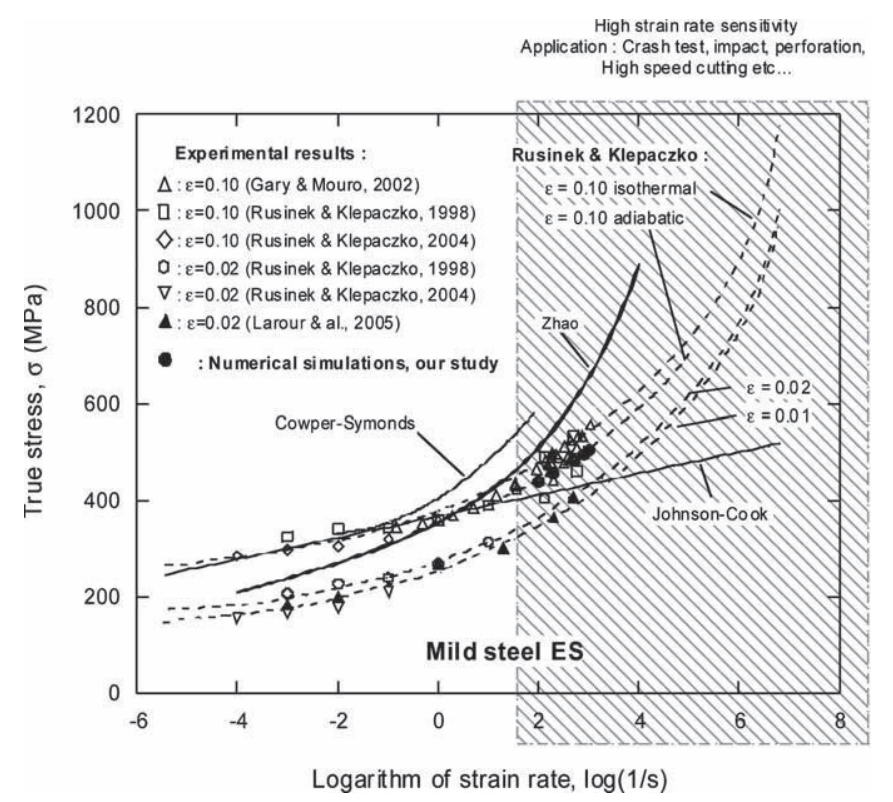

Fig. 1. Strain rate effects on the flow stress at small strain as predicted by different phenomenological formulations.

strain rates where adiabatic heating and material softening trigger a variety of instabilities and changes in strain fields. Concerning the comparison of constitutive relations with experimental results, Fig. 1 clearly shows their divergence from experiments. Cowper Symonds relation overestimates the strain rate sensitivity since it does not account for adiabatic heating. This relation has a completely different range of applications, mainly the analytical solutions of impulsively loaded structures like beams and plates, where the temperature coupling is negligible. On the other hand, the Johnson Cook accounts for thermal effects but clearly underestimates strain rate sensitivity. The semi-phenomenological constitutive equation herein discussed matches the experimental results in Fig. 1.

In order to verify and demonstrate the efficiency of the thermoviscoplastic model outlined in the first part of this paper a series of numerical simulations have been performed with ABAQUS explicit [10]. The aim was to simulate the impact tensile test of sheet metal specimens and to analyze the phenomenon of elastic and plastic wave propagation coupled with temperature (adiabatic heating). The simulations were performed for different initial lengths of specimens. Some of those specimen geometries are currently applied in experiments performed in LPMM-Metz.

\section{Remarks on experimental set-ups for dynamic tension tests, scale effect in dynamic tension}

The main objective of this study is to show the effect of initial length $l_{0}$, or more precisely, the effect of specimen design applied in impact tension tests. In fact, the study is performed to prove that "dynamic behavior" of a material being tested is strongly obscured by geometric effects like the initial length. Actually, many geometries are used in dynamic tension without normalization of such tests. For

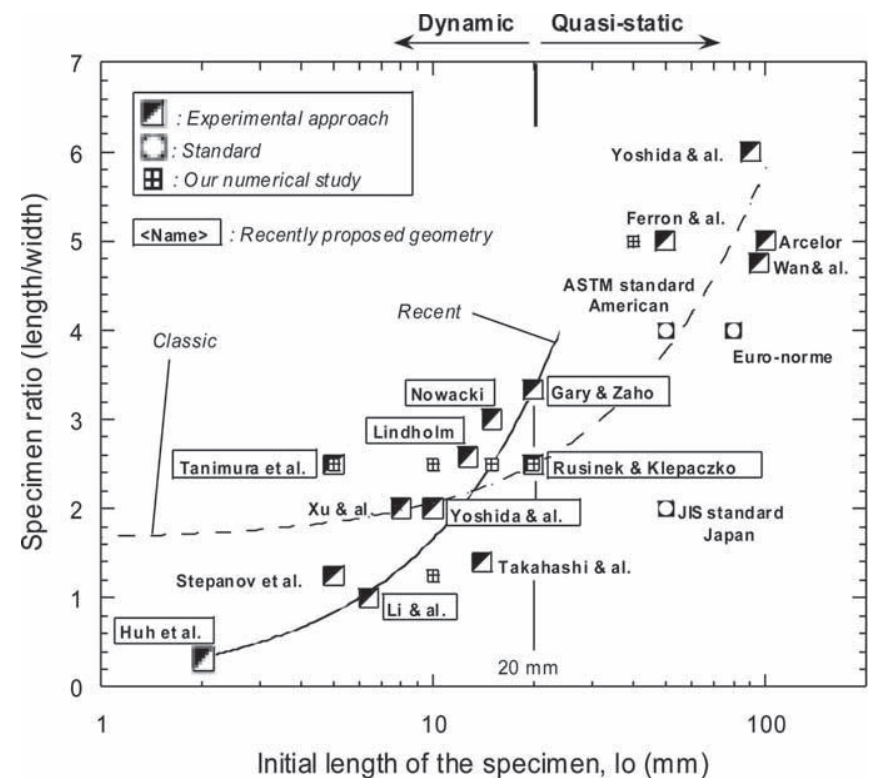

Fig. 2. Some specimen geometries used to study behavior of sheet steel in tension impact and quasi static tests.

example, Fig. 2 shows a comparison of some specimen designs used currently by different authors.

Some authors introduced original geometries with multiple specimens loaded at the same time $[8,13,27]$. This approach creates some technological problems with the specimen machining. On the other hand it allows the production of a mean material behavior, for example, six tensile segments deformed at the same time [8]. In all other cases the authors used a single-specimen geometry, where machining is much simpler, the initial length varying within the limits with $5 \leqslant l_{0} \leqslant 100 \mathrm{~mm}$ for most of them (with the exception of that due to Huh which is $2 \mathrm{~mm} \mathrm{long}$ ). Moreover, those different geometries are used with different equipment, like fast hydraulic machines and split Hopkinson set-ups [33]. In LPMM-Metz the true direct tension arrangement based on the inverted split Hopkinson bar has been introduced [15]. Such configuration of dynamic tension test with large displacement $\Delta X \approx 30 \mathrm{~mm}$ was first proposed by Klepaczko in 1995. Some experimental techniques also allow direct impact tension to be performed $[14,25,26,31,32,38]$. In conclusion, the result of using different geometries for the same type of equipment will be that some differences may appear due only to specimen dimensions $[25,37]$.

\section{Numerical simulation of impact tension test}

\subsection{Specimen geometries and simulation model}

During the numerical simulations six geometries have been considered, Table 1, with the initial length varying as discussed previously from 5 to $100 \mathrm{~mm}$; the thickness is assumed constant $t \quad 0.8 \mathrm{~mm}$. Of course, the range of length around $l_{0} \quad 100 \mathrm{~mm}$ would never be used in dynamic loading but it is included just to cover a standard 
Table 1

Different geometries used during numerical simulations, dimensions in $\mathrm{mm}$

\begin{tabular}{lcclll}
\hline Name & $l_{0}(\mathrm{~mm})$ & $w(\mathrm{~mm})$ & Ratio $l_{0} / w$ & $r(\mathrm{~mm})$ & $h(\mathrm{~mm})$ \\
\hline$S_{1}$ (LPMM) & 10 & 8 & 1.25 & 6 & 25 \\
$S_{2}$ (LPMM) & 20 & 8 & 2.5 & 6 & 25 \\
$S_{3}$ & 40 & 13 & 3.076 & 6 & 25 \\
$S_{4}$ & 100 & 13 & 7.692 & 6 & 25 \\
$A_{0}$ & 10 & 4 & 2.5 & 5 & 10 \\
Ref. [12] & 5 & 2 & 2.5 & 0.6 & 10.4 \\
\hline
\end{tabular}

LPMM: Laboratory of Physics and Mechanics of Materials (University of Metz).

length and accentuate some effects such as inertia at impact loading.

A representative mesh of the model used in the numerical simulations is shown in Fig. 3. This optimized mesh has been obtained by a convergence study, and no geometric defects were introduced along the axis. A 3D calculation has been performed using an 8-node reduced integration hourglass control solid element (C3D8R in ABAQUS notation) [10]. The boundary conditions, as shown in Fig. 3, are: the displacement of the left specimen side is blocked and the right side is loaded by an impact velocity $V_{0}$, inducing a dynamic loading which triggers a combination of elastic and plastic wave propagation. The imposed velocity $V_{0}$ remains constant during the process of plastic deformation.

All simulations have been performed with the constitutive relations outlined in the first part of this paper, the material adopted is the mild steel ES [4]. During the numerical simulations the constitutive relation has been coupled with an original thermoviscoplastic algorithm allowing to calculate the equivalent quantities. The details are reported in $[39,40]$. To demonstrate the efficiency of our thermoviscoplastic approach, the stress strain curves obtained through numerical simulation of tensile tests at two different strain rates were compared to that given by Eqs. (1) (7). As shown in Fig. 4, the compared curves are coincident

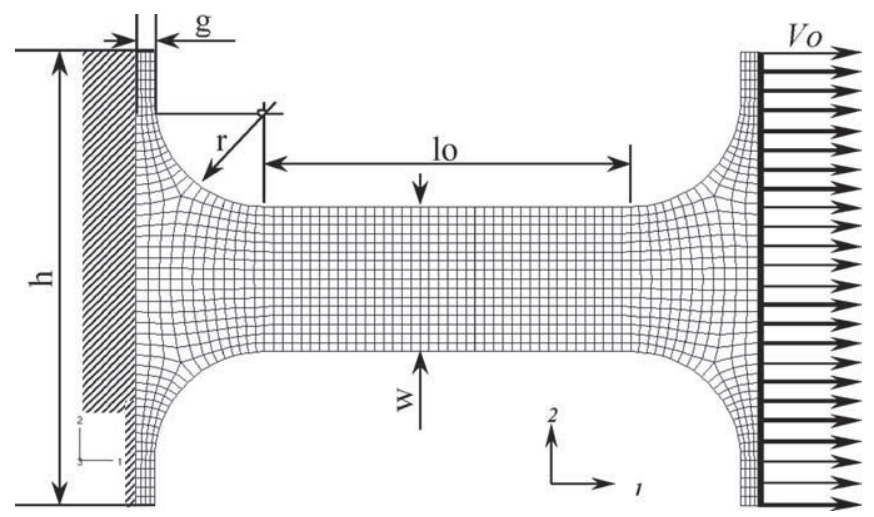

Fig. 3. Initial and boundary conditions, specimen dimensions and representative mesh used during the numerical simulations with ABA QUS/Explicit.

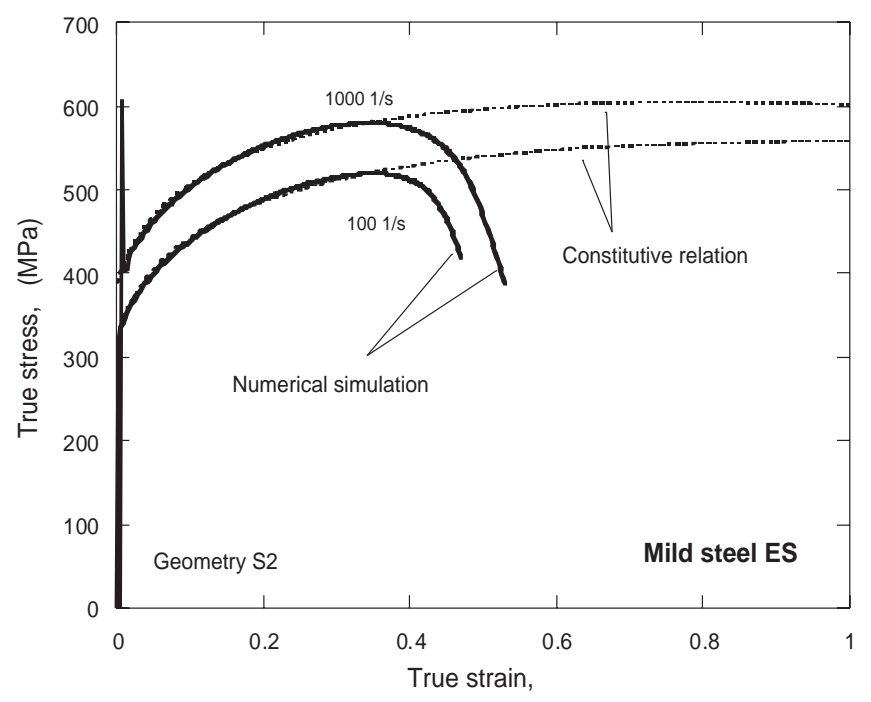

Fig. 4. Comparison between VUMAT subroutine and constitutive rela tion, Eqs. (1) (6), prediction of thermoviscoplastic behavior for two strain rates $\dot{\bar{\varepsilon}}^{\mathrm{p}} 10^{2} \mathrm{~s}^{1}$ and $\dot{\bar{\varepsilon}}^{\mathrm{p}} 10^{3} \mathrm{~s}^{1}$.

and the difference appears only when the necking takes place since the constitutive relation defines only the homogeneous behavior. The consistency algorithm has also been validated for the Taylor test by comparing the numerical results obtained with ABAQUS (commercial version) and ABAQUS coupled with this algorithm (VUMAT) for a Johnson Cook hardening equation. The results yield a good agreement [39].

Having demonstrated the efficiency of the constitutive relation and consistent algorithm $[39,40]$ a FE analysis of the dynamic tension test is reported next to complete some previous FE simulations such as dynamic ring expansion [41], crash-box test, Taylor test [39] and shear test [2].

\subsection{Analysis of the numerical results}

The first task was to compare the strain rate effects for all geometries studied for strain rates varying from $10^{2} \mathrm{~s}{ }^{1}$ to $10^{3} \mathrm{~s}^{1}$. In this range of strain rates adiabatic heating occurs. In fact, for this material the strain rate which defines the transition between isothermal and adiabatic behavior is approximately $10 \mathrm{~s}{ }^{1}$. This level of strain rate causes a change of the strain hardening coefficient due to thermal softening. For strain rates lower than $10 \mathrm{~s}^{1}$ (isothermal conditions) the curve $\sigma\left(\varepsilon^{\mathrm{p}}, \dot{\varepsilon}^{\mathrm{p}}, T\right)$ shows the same order of strain hardening (the translated shape). The output stress has been defined by two different definitions. In the first case, the force has been calculated on the opposite side of impact (left) and in the second case the force has been calculated on the impact side (right), Fig. 3. The numerical results obtained in the impact tension test by these two approaches allow us to define if a force equilibrium is reached between the two specimen sides, Table 2. Only geometries currently used in industries were studied. Thus, we can observe that for the long specimen the equilibrium is quickly lost in comparison with the short one. 
Table 2

Analysis of mechanical equilibrium in tension between input and output forces

\begin{tabular}{|c|c|c|c|c|c|c|c|c|c|c|}
\hline \multirow[t]{2}{*}{ Geometry } & \multicolumn{2}{|l|}{$100(1 / \mathrm{s})$} & \multicolumn{2}{|l|}{$200(1 / \mathrm{s})$} & \multicolumn{2}{|l|}{$500(1 / \mathrm{s})$} & \multicolumn{2}{|l|}{$800(1 / \mathrm{s})$} & \multicolumn{2}{|c|}{$1000(1 / s)$} \\
\hline & $\begin{array}{l}\text { Necking } \\
\text { place }\end{array}$ & $\begin{array}{l}\text { Equilibrium } \\
2 \text { sides }\end{array}$ & $\begin{array}{l}\text { Necking } \\
\text { place }\end{array}$ & $\begin{array}{l}\text { Equilibrium } \\
2 \text { sides }\end{array}$ & $\begin{array}{l}\text { Necking } \\
\text { place }\end{array}$ & $\begin{array}{l}\text { Equilibrium } \\
2 \text { sides }\end{array}$ & $\begin{array}{l}\text { Necking } \\
\text { place }\end{array}$ & $\begin{array}{l}\text { Equilibrium } \\
2 \text { sides }\end{array}$ & $\begin{array}{l}\text { Necking } \\
\text { place }\end{array}$ & $\begin{array}{l}\text { Equilibrium } \\
2 \text { sides }\end{array}$ \\
\hline$S_{1}$ & Middle & Yes & Middle & Yes & Middle & Yes & Middle & Yes & Middle & Yes \\
\hline$S_{2}$ & Middle & Yes & Middle & Yes & Middle & Yes & Middle & Yes & Middle & Yes \\
\hline$S_{3}$ & Middle & Yes & Left & Yes & Left & Yes & Right & No & Right & No \\
\hline$S_{4}$ & Middle & Yes & Left & Yes & Right & No & Right & No & Right & No \\
\hline
\end{tabular}

The comparison is shown in Fig. 5 for the long specimen (geometry S4) and different strain rates. Thus, for imposed strain rate $\dot{\varepsilon}^{\mathrm{p}}=100 \mathrm{~s}^{-1}$ the two forces are equal but for strain rates higher than $200 \mathrm{~s}^{1}$ loss of the equilibrium is observed between the input and output forces. This phenomenon is amplified with strain rate or increase of impact velocity. For $\dot{\varepsilon}^{\mathrm{p}}=10^{3} \mathrm{~s}^{-1}$, the difference is significant with a fast and almost instantaneous decrease of the input force. The same observation has been reported in [35], Fig. 5(b). In fact, this velocity $V_{0} \quad 100 \mathrm{~m} / \mathrm{s}$ corresponds to apparition of the critical impact velocity (CIV) inducing a trapping of plastic deformation close to the impact side. It is also observed that the CIV defined for ES steel is close to the value found in [35], Figs. 5(a) and (b), corresponding to mild steel. The phenomenon of the CIV will be discussed in the next section. In the present section, only behavior of the homogeneous field (stress strain) will be reported to analyze the effect of strain rate in adiabatic conditions on the macroscopic behavior of steel sheet as a function of the initial geometry.

The first comparison in terms of strain rate is shown in the following pictures for all geometries $S_{i}$, see also Table 1 . For each case, a positive strain rate sensitivity is observed inducing a stress increase with the strain rate at deformation larger than $\varepsilon^{\mathrm{p}} \geqslant 0.1$. However, for geometries $S_{3}$ and $S_{4}$ inertia effects are observed beginning with strain rate equal or higher than $\dot{\varepsilon}^{p} \geqslant 500 \mathrm{~s}^{-1}$. This is found at the initial stages of loading. In this case, during the first period a "negative" strain rate sensitivity is observed, more precisely for $S_{4}$ geometry, Fig. 6(d). The main reason is the inertia effect. After stabilization of the transmitted signal a positive rate effect is found, but the strain level of instability is sensitive to strain rate, Figs. 6(c) and (d), in comparison with other geometries, Figs. 6(a) and (c). For $S_{4}$ geometry this effect is also related to the CIV since $\dot{\varepsilon}^{\mathrm{p}}=10^{3} \mathrm{~s}^{-1}$ corresponds to $V_{0} \quad 100 \mathrm{~m} / \mathrm{s}$ for $l_{0} \quad 100 \mathrm{~mm}$.

Next, the geometry effect was analyzed for an imposed strain rate, Figs. 7(a) and (b), for all geometries $S_{i}$ and two geometries in addition. The first one is the specimen used by Tanimura and Mimura [12] and the second is the geometry used in LPMM in experiments to validate the numerical simulations which enabled a high strain rate close to $\dot{\varepsilon}_{\max }^{\mathrm{p}} \approx 10^{3} \mathrm{~s}^{-1}$ to be reached. Two comparisons are shown in Figs. 7(a) and (b) for strain rates $\dot{\varepsilon}^{\mathrm{p}}=10^{2} \mathrm{~s}^{-1}$ and $\dot{\varepsilon}^{\mathrm{p}}=10^{3} \mathrm{~s}^{-1}$. Those strain rates are covering the range in the crash test. For $\dot{\varepsilon}=10^{2} \mathrm{~s}^{-1}$ the difference is not very important for all $S_{i}$ geometries and $A_{0}$. The disagreement appears only with the specimen used by Tanimura where $l_{0} 5 \mathrm{~mm}$ for which we can observe higher stress level (in homogeneous strain field) but also a great difference in the ductility and instability strain levels, Figs. 7(a) and (b).

Using a local analysis, an explanation has been found concerning the difference observed for the Tanimura specimen. In fact, due to its small initial length, the localization of the plastic strain appears quickly which induces at the same time an increase of the local strain rate in the specimen. For example, for the macroscopic strain rates imposed
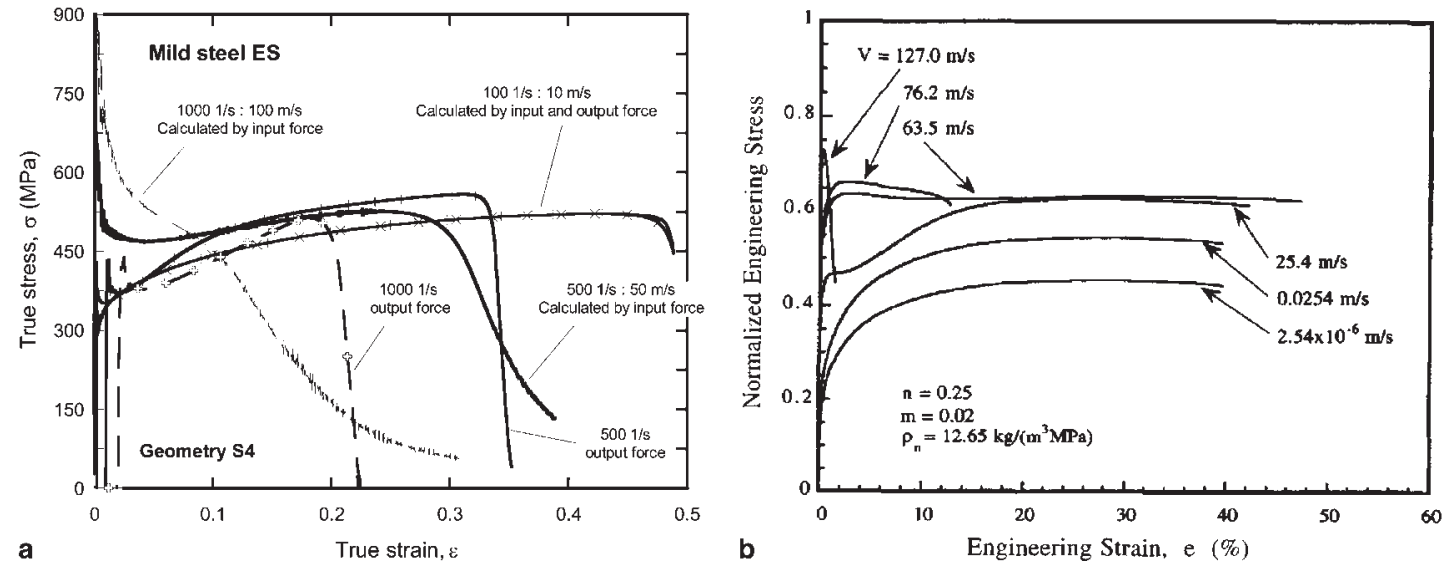

Fig. 5. (a) Comparison of input and output forces obtained by numerical simulation for mild steel ES. (b) Numerical results obtained by another numerical simulation for steel and definition of CIV [39]. 

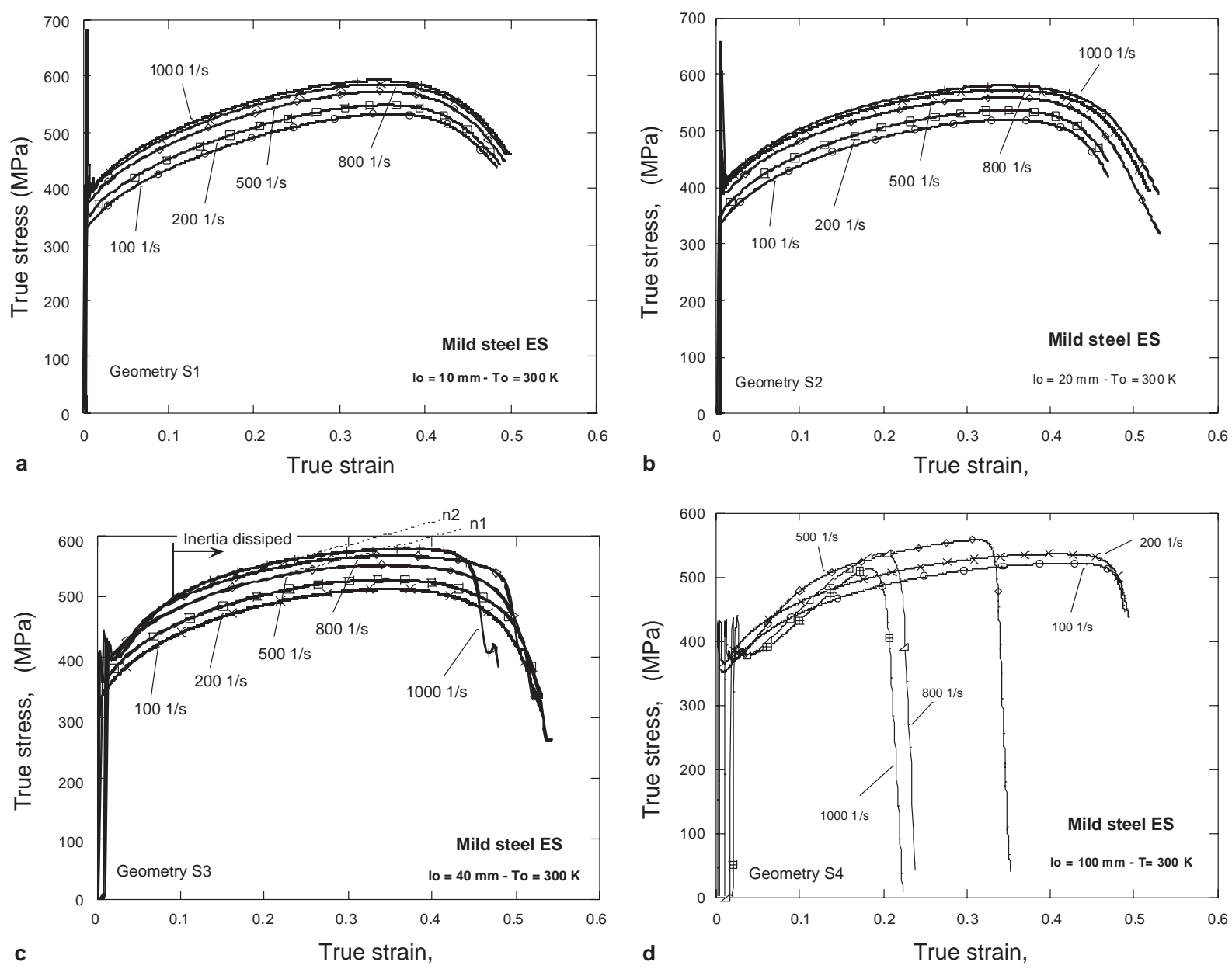

Fig. 6. Numerical predictions of rate effects for different geometries using output force to define stress levels: (a) $l_{0}=10 \mathrm{~mm}$; (b) $l_{0}=20 \mathrm{~mm}$; (c) $l_{0}=40 \mathrm{~mm}$ and (d) $l_{0}=100 \mathrm{~mm}$.
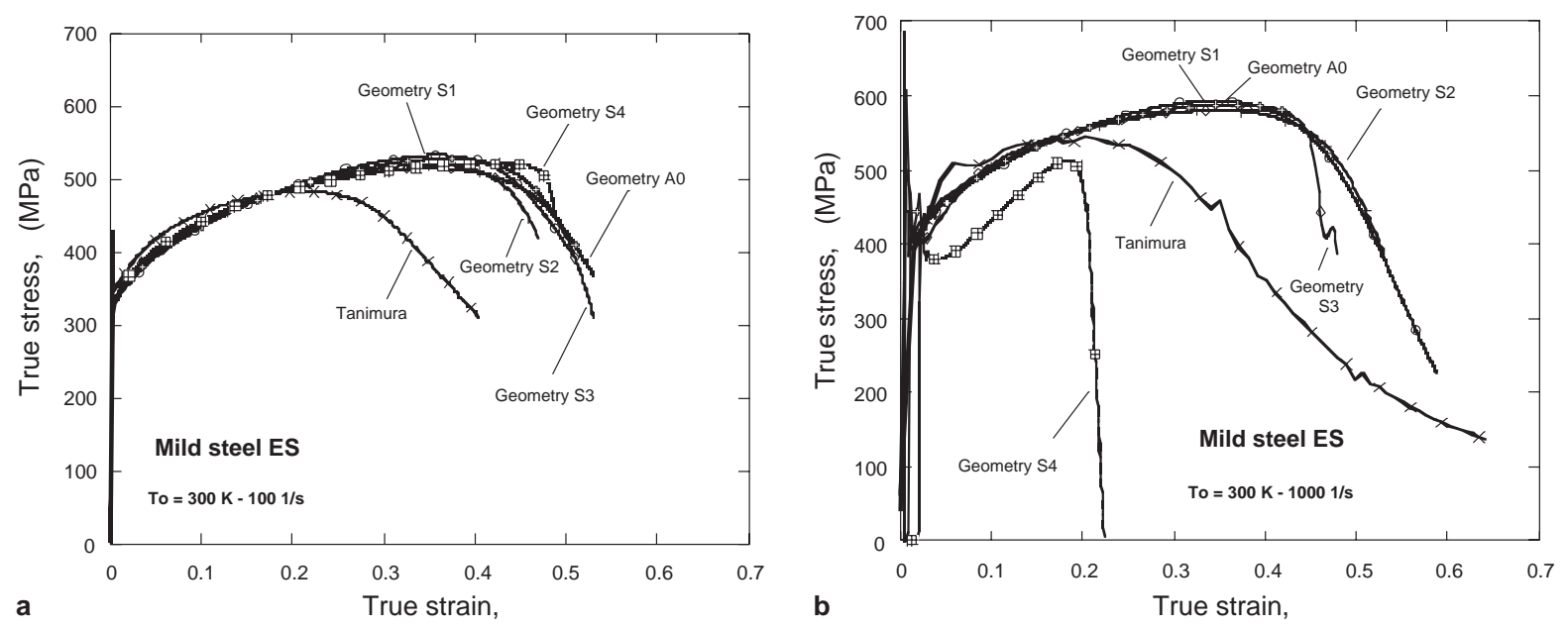

Fig. 7. Effect of initial length for different strain rates imposed: (a) $\dot{\bar{\varepsilon}}^{\mathrm{p}} 10^{2} \mathrm{~s}^{1}$; (b) $\dot{\bar{\varepsilon}}^{\mathrm{p}} 10^{3} \mathrm{~s}{ }^{1}$.

$\dot{\varepsilon}^{\mathrm{p}}=10^{2} \mathrm{~s}^{-1}$ and $\dot{\varepsilon}^{\mathrm{p}}=10^{3} \mathrm{~s}^{-1}$ the local strain rate calculated by numerical simulation just before plastic localization is, respectively, $\dot{\varepsilon}^{\mathrm{p}} \approx 122 \mathrm{~s}^{-1}$ and $\dot{\varepsilon}^{\mathrm{p}}=1273 \mathrm{~s}^{-1}$, Figs. 8(a) and (b). This local effect induces an increase of the macroscopic stress level. Thus, if we use the local strain rate intensity to calculate the curve $\sigma-\left.\varepsilon^{\mathrm{p}}\right|_{\varepsilon_{\varepsilon_{c}}^{\mathrm{p}}}$ with the constitutive relation defined by Eqs. (1) (7), a good agreement is found between the numerical simulations and prediction by this constitutive 

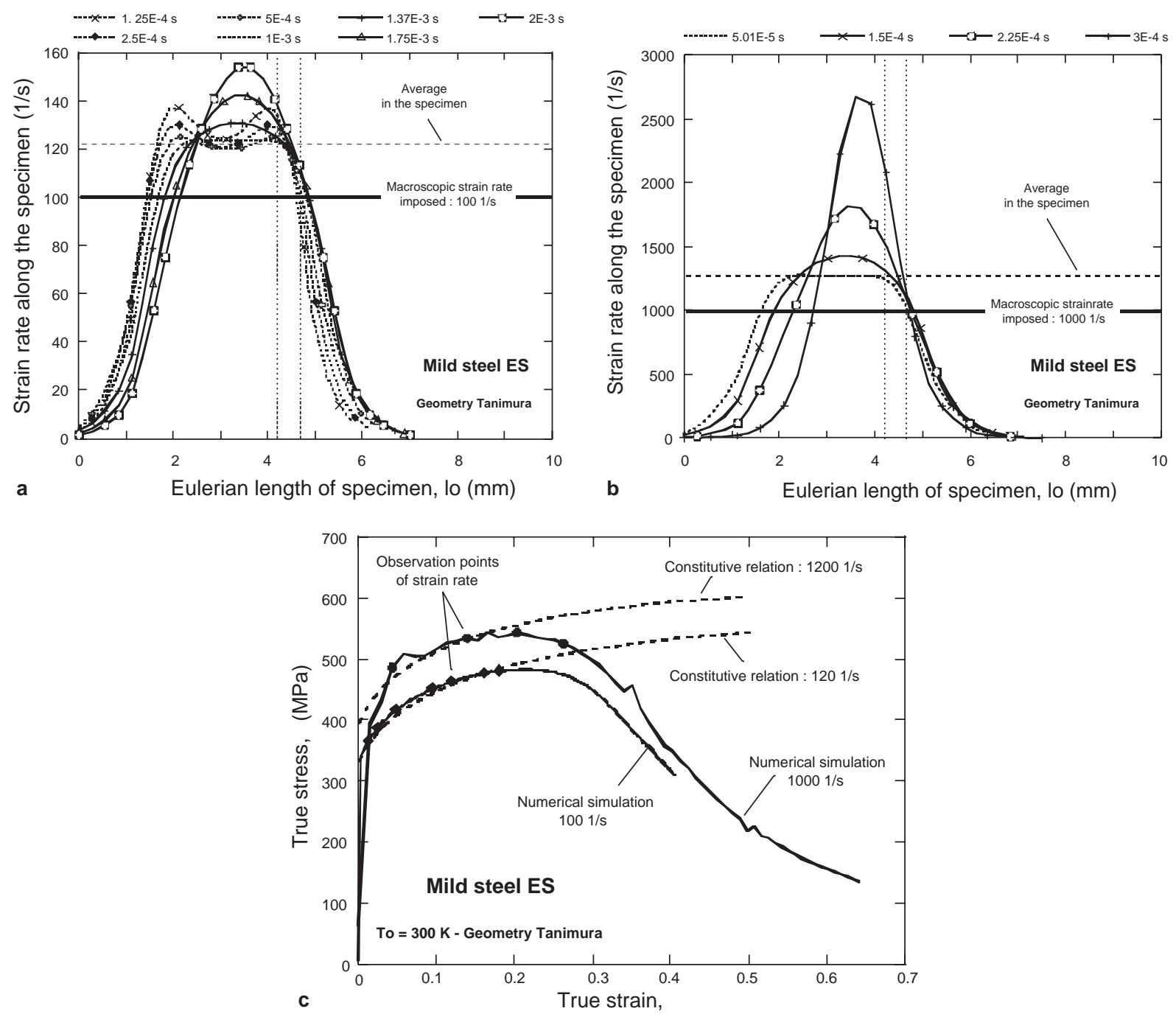

Fig. 8. (a) and (b) Comparison between macroscopic and local strain rate for short specimen $l_{0}=5 \mathrm{~mm}$; (c) prediction using Eqs. (1) (6) with local strain rate obtained by numerical simulations.

relation, Fig. 8(c). In conclusion, the size of the specimen cannot be reduced infinitely. Using the numerical results the lower limit in terms of the initial length is close to $l_{0} 10 \mathrm{~mm}$. Indeed for all geometries $S_{i}$, such an effect is not observed.

For example, for $S_{2}$ geometry, the local strain rate $\dot{\varepsilon}_{\text {local }}^{\mathrm{p}}$ is much lower at the beginning of loading in order to reach progressively the value of the macroscopic imposed plastic strain rate $\dot{\varepsilon}^{\dot{p}}$, Fig. 9(a). Therefore, the macroscopic behavior determined during experiment, which is an average behavior of the specimen volume $\Omega$, could be well defined and close to the real response of the material, $\sigma-\left.\varepsilon^{\mathrm{p}}\right|_{\varepsilon^{\mathrm{p}}}$, Fig. 9(b), when the mean values are used

$\sigma(\vec{r}, t)=\frac{1}{\Omega} \iiint \sigma_{\text {local }}(\vec{r}, t) \mathrm{d} \Omega$,

$\varepsilon^{\mathrm{p}}(\vec{r}, t)=\frac{1}{\Omega} \iiint \varepsilon_{\text {local }}^{\mathrm{p}}(\vec{r}, t) \mathrm{d} \Omega$,

where $\vec{r}$ are the spatial coordinates in the volume $\Omega$.
The specimen with the initial length $l_{0} \quad 20 \mathrm{~mm}\left(S_{2}\right.$ geometry) seems to be the best compromise since it allows the correct stress level to be reached and also such a specimen assures sufficient ductility in comparison with long specimens where $20<l_{0}<40 \mathrm{~mm}$, Fig. 6(b) and Figs. 9(b) and (c). The initial length of $l_{0} \quad 20 \mathrm{~mm}$ seems to define correctly the transition between quasi-static and dynamic tension tests. Comparing the stress level $\Delta \sigma_{\max }=\sigma_{l_{0}}^{\max }-$ $\sigma_{l_{0}}^{\max } 100 \mathrm{~mm}$ at $\dot{\varepsilon}^{\mathrm{p}}=100 \mathrm{~s}^{-1}$, we found for $l_{0} 10 \mathrm{~mm}$, $\Delta \sigma_{\max } \approx 12 \mathrm{MPa}$ and for $l_{0} \quad 20 \mathrm{~mm}, \Delta \sigma_{\max } \approx 1 \mathrm{MPa}$ with the same strain hardening rate.

In Fig. 10 a comparison is shown between experiment and numerical results in terms of ductility. Thus, the more the length increases, the more ductility is observed for the same strain rate imposed. It can be also observed that the ductility decreases linearly with the increase of strain rate, as in the experiment. To conclude, the numerical prediction for $A_{0}$ geometry shows a good agreement with experimental results for the same geometry. This point is very 

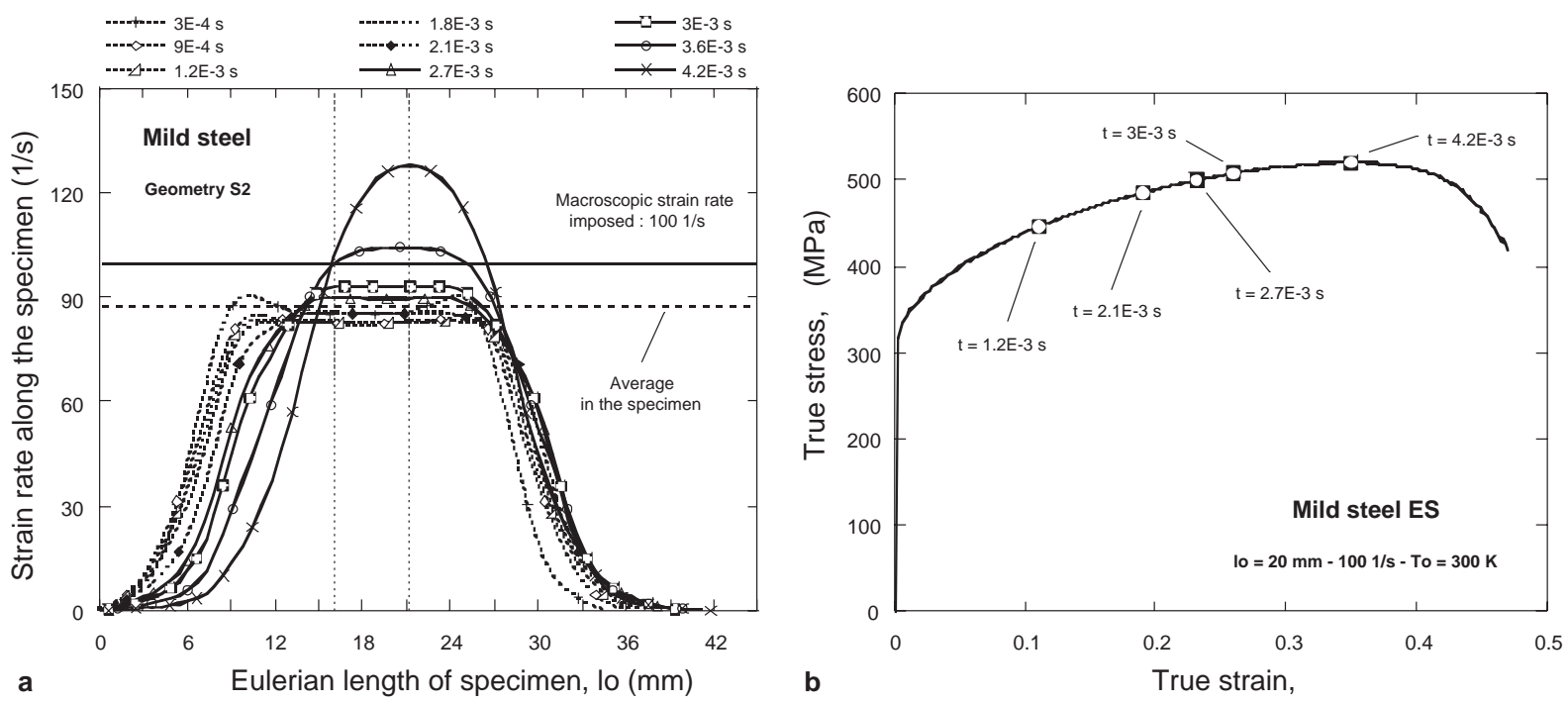

Fig. 9. (a) Intensity of local strain rate in comparison with strain rate imposed for $l_{0}=20 \mathrm{~mm}$. (b) Thermoviscoplastic behavior obtained by numerical simulation for $\dot{\bar{\varepsilon}}^{\mathrm{p}} 100 \mathrm{~s}^{1}$ and $l_{0}=20 \mathrm{~mm}$.

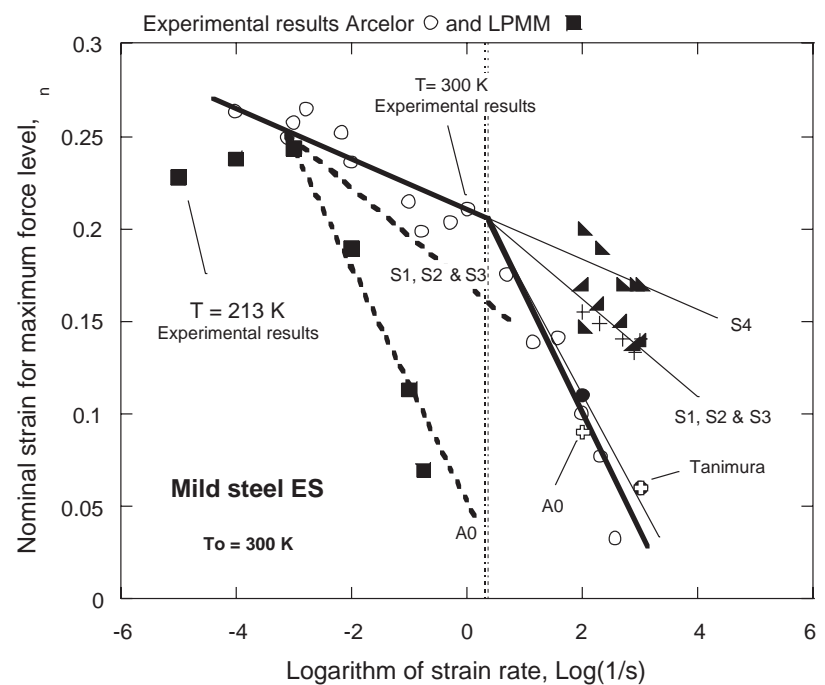

Fig. 10. Comparison of ductility between experimental $(\bigcirc \mathbf{\square})[45]$ and numerical results with strain rates.

important in modeling the thermoviscoplastic behavior. It is essential to have a large volume of plastic deformation to define precisely the hardening and also to collect information on the thermal softening which induces a decrease of the flow stress. This effect is generally more important for $\varepsilon \geqslant 0.1$ due to plastic work converted into heat, Eq. (7).

It is clear that a specimen with small dimensions, for example specimen $A_{0}$ reported in [12], leads to difficulties in determining real material behavior at high strain rates and low temperatures, as shown in Fig. 10. Indeed, for low temperatures as generally observed the ductility decreases, Fig. 10. In that case only numerical prediction has been performed at room temperature. However, assuming the same slope $\partial \varepsilon_{n} /\left.\partial \dot{\varepsilon}^{\mathrm{p}}\right|_{T}$ obtained at room temperature in order to predict behavior at low temperature, we observe that at low temperature $T 213 \mathrm{~K}$ the strain rate which will be adequate is $\dot{\varepsilon}^{\mathrm{p}} \approx 1 \mathrm{~s}^{-1}$. With the constitutive relation used in this paper, an estimation has also been performed concerning the adiabatic temperature increase with strain rate. In the first case only the shape of the $\left.\sigma\left(\varepsilon^{\mathrm{p}}, T\right)\right|_{\varepsilon^{\mathrm{p}}}$ curve has been considered and good agreement has been found with experiment, Fig. 11(a), this time in comparison with another kind of steel (TRIP 800). The second comparison is reported in Fig. 11(b). In this case the prediction seems to be in agreement concerning the temperature increase $\left.\Delta T\right|_{e^{\mathrm{p}}}$ with strain rate. A good continuity of temperature increase between the quasi-static test obtained by experiment and numerical simulation performed at high strain rate in adiabatic conditions is found.

The difference observed in Fig. 11(a) is due to the strain hardening and also due to slightly different stress and strain levels. One can observe in Fig. 11(b) that the slope of the curve $\Delta T-\log \left(\dot{\varepsilon}^{\mathrm{p}}\right)$ is always similar without any influence from the material tested [46]. The average slope is close to $78 \mathrm{~K} / \log (1 / s)$. The numerical simulations have also enabled us to find a similar value, Fig. 11(b). The numerical and experimental results have been obtained with $S_{2}$ geometry. To further validate the recommendation concerning the geometry with $l_{0} \quad 20 \mathrm{~mm}$, a comparison of experimental results is shown in Fig. 12. In this case the strain rate effect obtained for $l_{0} \quad 100$ and $20 \mathrm{~mm}$ in the range of quasi-static loading is identical for both geometries. Thus, using the specimen with $l_{0} \quad 20 \mathrm{~mm}$ a good agreement with larger specimens is obtained of the strain rate effect as well as of the stress level up to a strain rate $\approx 10^{2} \mathrm{~s}{ }^{1}$.

In conclusion the geometry with the gage length of $l_{0} \quad 20 \mathrm{~mm}$ and the width of $w \quad 8 \mathrm{~mm}\left(S_{2}\right.$ geometry) allows determination not only the dynamic behavior but also the behavior at quasi-static range of strain rates. Moreover, the rate of hardening observed for $S_{2}$ and $S_{4}$ geometry is very close, which is not the case for $l_{0} 10 \mathrm{~mm}$ and 

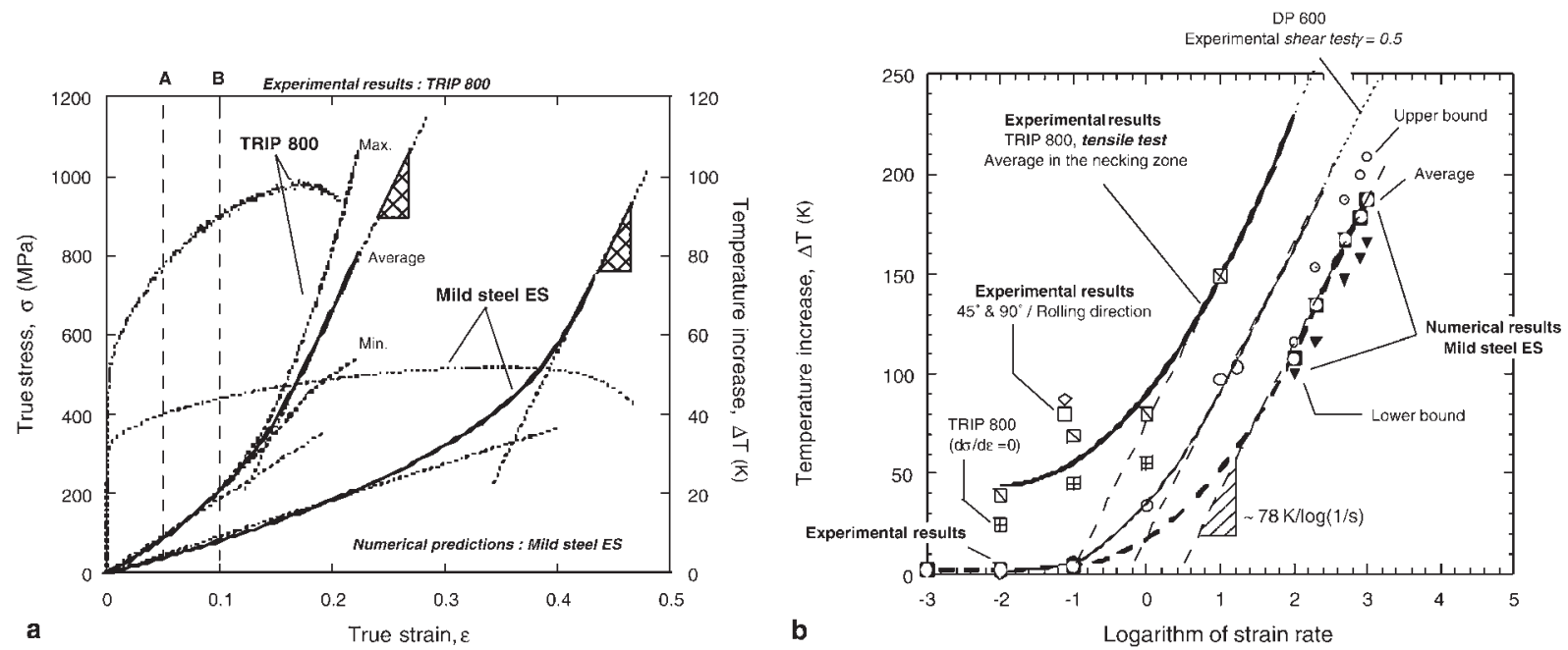

Fig. 11. (a) Comparison between experimental and numerical results concerning $\bar{\sigma}\left(\bar{\varepsilon}_{\mathrm{p}}\right)$ curves; (b) prediction of temperature increase with strain rate and comparison with experimental results obtained by thermography.

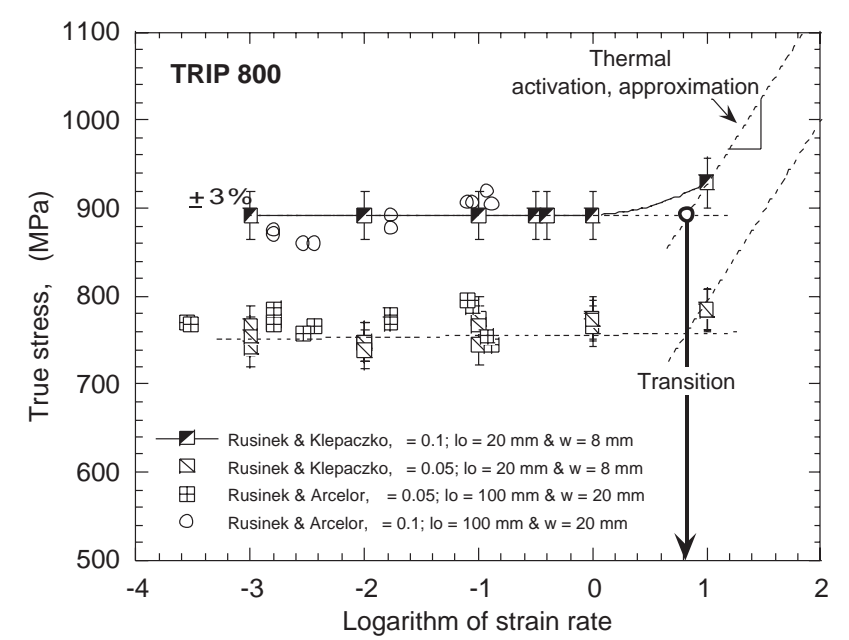

Fig. 12. Strain rate effects for two specimen geometries, $l_{0}=20 \mathrm{~mm}$ and $l_{0}=100 \mathrm{~mm}$.

w $8 \mathrm{~mm}$. The difference increases with plastic strain. The same conclusion was reached from experiments.

\section{Estimation of the CIV for mild steel ES by an analytical approach}

Several experimental studies are reported in the literature how to determine the CIV in tension for different materials $[11,16,17]$. The CIV is caused by trapping of plastic deformation triggered by plastic waves. If the impact velocity is high enough the plastic wave speed in adiabatic conditions near the impact end is zero. Thus, this phenomenon is directly related to the thermoviscoplastic behavior of material since the plastic wave speed $C_{\mathrm{p}}$ can be found by Eq. (14). The CIV may be defined as an intrinsic mechanical property without any effect of the specimen geometry, as is shown in Fig. 13(a) [34]. In this figure the maximum energy is always reached for the same impact velocity whatever the initial length of the specimen $l_{0}$. How- ever, for lower impact velocities, the process of necking depends on the initial length. For a long specimen, Fig. 13(b), it is observed that the necking moves along the specimen as a function of the impact velocity until reaching the CIV.

The phenomenon of the CIV is relatively important since the final stage of specimen deformation is, of course, failure. A combination of CIV and failure may be classified as an example of dynamic failure mechanics, a discipline in the stage of early development. No initial cracks are assumed and a solid is loaded in a short time interval, and a more or less uniform plasticity field develops. But after a short time, due to local strain concentrations, temperature gradients appear caused by adiabatic heating, and localization of plastic field leads to failure. The problem of one-dimensional elastic and rate-independent plastic wave propagation is governed by the following equation $[16,42]$ :

$\frac{\partial^{2} U_{x}}{\partial t^{2}}=C_{i}^{2}(\varepsilon) \frac{\partial^{2} U_{x}}{\partial x^{2}}$,

where $U_{x}$ is the material particle displacement and $C_{i}$ is defined as the wave speed.

The general solution of Eq. (10) is in the form of Eq. (11) where the displacement $U_{x}$ is defined by the following relation:

$U_{x}(\phi, \psi)=f(\phi)+g(\psi)$,

where $f$ and $g$ define the wave propagation in the positive and negative directions. This solution of wave propagation has the property that the displacement can be written as a function of independent variables $\phi$ and $\psi$ which depend on the wave speed $C_{i}$, space variable $x$ and time $t$ :

$\phi=x-C_{i} t \quad$ and $\quad \psi=x+C_{i} t$.

The effect of adiabatic heating on the plastic wave speed leads to its decrease. The expressions for the particular 

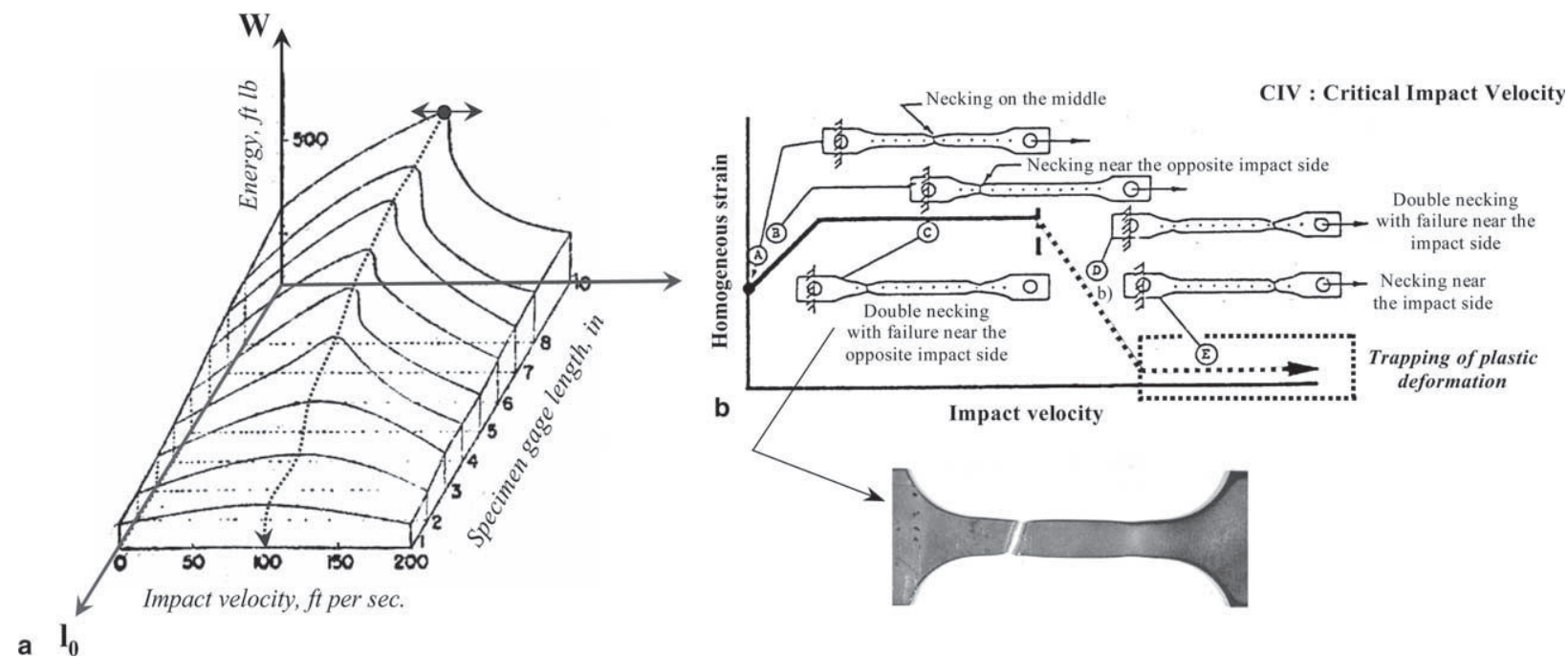

Fig. 13. (a) Definition of the CIV with knowledge of the energy absorbed for different initial length [34]. (b) Schematic representation of the impact velocity effect on the process of dynamic necking [35].

wave speeds in a one-dimensional state of stress are (elastic or plastic):

$C_{0}(T)=\left(\frac{E(T)}{\rho}\right)^{1 / 2} \quad$ elastic wave

$C_{\mathrm{p}}\left(\varepsilon^{\mathrm{p}}, T\right)=\left(\left.\frac{1}{\rho} \frac{\mathrm{d} \sigma\left(\varepsilon^{\mathrm{p}}, T\right)}{\mathrm{d} \varepsilon^{\mathrm{p}}}\right|_{\varepsilon^{\mathrm{p}}}\right)^{1 / 2}$ plastic wave,

With $\frac{E(T)}{E_{0}}=1-\frac{T}{T_{\mathrm{m}}} \exp \left(\theta^{*}\left(1-\frac{T_{\mathrm{m}}}{T}\right)\right)$,

where $E(T)$ is the temperature dependent Young's modulus. Moreover, it was shown by von Karman and Duwez [16], that the speed of plastic waves reaches zero when the tangent modulus is zero, i.e., for $\mathrm{d} \sigma / \mathrm{d} \varepsilon^{\mathrm{p}}=0$. Then, if the impact velocity is high enough, large values of $\varepsilon^{\mathrm{p}}$ lead to a stagnation of the plastic wave and localization of plastic deformation. Failure appears at the impacted side of the specimen and the remainder of the bar is not deformed plastically. In this way the CIV has been derived. Beyond that velocity the localization and failure appear near the impact side of a bar. In experiment the energy of impact is absorbed in a very narrow zone of the bar near the impact side. An analytical method to obtain the CIV is by using the integral relation between pulling velocity $V_{0}$ and the plastic deformation behind the plastic wave front $\varepsilon_{\mathrm{wf}}^{\mathrm{p}}$ as proposed by von Karman and Duwez. Neglecting the elastic deformation, we arrive at the equation:

$V_{0}=\left.\int_{0}^{e_{\mathrm{wf}}^{\mathrm{p}}} C_{\mathrm{p}}\left(\varepsilon^{\mathrm{p}}, T\right)\right|_{\varepsilon^{\mathrm{p}}} \mathrm{d} \varepsilon^{\mathrm{p}}$.

When the upper limit of the integral equals the deformation at instability, $V_{0}$ equals the CIV. A more complete expression of this integral equation accounting for strain rate and temperature can be found in $[1620,23,24]$ as the sum of two terms, respectively, due to the elastic and plastic fields. The analytical approach presented above was confirmed by the experimental observations of Duwez and Clark [21], Wood [22] and Pond and Glass [36]. In the early analyses of the CIV an analytic solution was derived by application of quasi-static constitutive relation in isothermal conditions [16]. This solution is incomplete since the upper bound of the integral, Eq. (15), is never reached in the isothermal conditions when a parabolic strain hardening is assumed. In general, all materials are sensitive to thermal and strain rate effects in dynamic loading as shown in Fig. 1. Based on work in [16 20], a more complete approach, including temperature effects to estimate CIV in tension, has been obtained here by the numerical solution of the equation, Eq. (14), using the more precise constitutive equation, Eqs. (1) (7). In this case a generalization of the method to obtain the CIV is reported using a thermoviscoplastic approach in adiabatic conditions. The integral relation between $V_{0}$ and $\varepsilon_{\mathrm{wf}}^{\mathrm{p}}$ taking into account hardening, strain rate sensitivity and temperature sensitivity is as follows:

$$
\begin{aligned}
V_{0}\left(\varepsilon^{\mathrm{p}}, \dot{\varepsilon}^{\mathrm{p}}, T\right)= & \frac{1}{\sqrt{ } \rho} \int_{\varepsilon_{\mathrm{e}}}^{\varepsilon_{\mathrm{w} f}^{\mathrm{p}}}\left\{\left[1-\frac{T}{T_{\mathrm{m}}} \exp \left(\theta^{*}\left(1-\frac{T_{\mathrm{m}}}{T}\right)\right)\right]\right. \\
& \left.\times\left[B\left(\dot{\varepsilon}^{\mathrm{p}}, T\right) n\left(\dot{\varepsilon}^{\mathrm{p}}, T\right)\left(\varepsilon_{0}+\varepsilon^{\mathrm{p}}\right)^{n\left(\varepsilon^{\mathrm{p}}, \mathrm{T}\right)-1}\right]\right\}^{1 / 2} \mathrm{~d} \varepsilon^{\mathrm{p}},
\end{aligned}
$$

$\Delta T\left(\varepsilon^{\mathrm{p}}, \dot{\varepsilon}^{\mathrm{p}}\right)=\frac{\beta}{\rho C_{\mathrm{p}}} \int_{\varepsilon_{\mathrm{e}}}^{\varepsilon^{\mathrm{p}}} \sigma\left(\varepsilon^{\mathrm{p}}, \dot{\varepsilon}^{\mathrm{p}}, T\right) \mathrm{d} \varepsilon^{\mathrm{p}}$.

Now, in order to find the CIV, the upper limit of the integral is taken from the condition $\partial \sigma / \partial \varepsilon^{\mathrm{p}}=0$, which is consistent with the phenomenon of plastic wave trapping at the impacted end of the specimen $C_{\mathrm{p}} \quad 0$. This could be done since adiabatic thermal softening is now accounted for by the constitutive equation and the energy balance. Fig. 14 shows different values of the integral, Eq. (16), using this upper limit, for a range of plastic strain rates. 

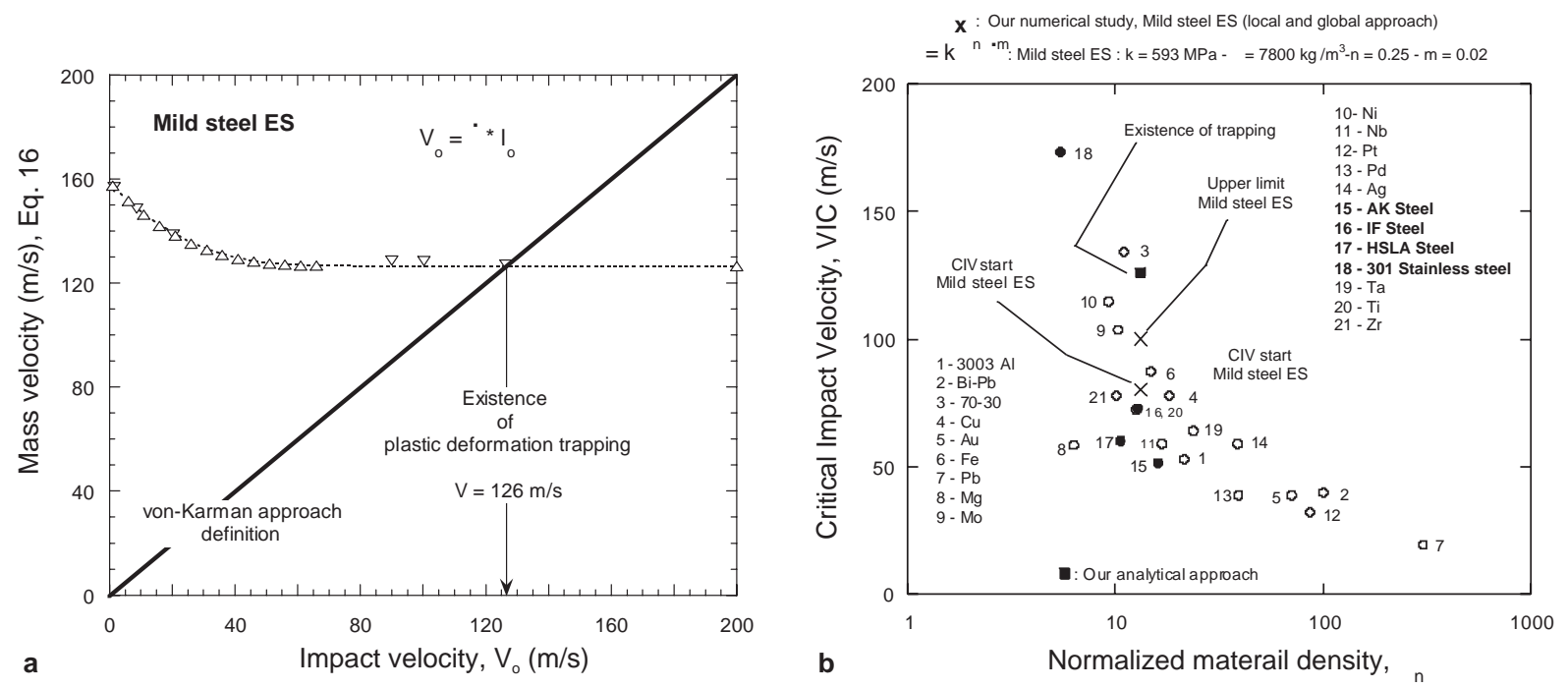

Fig. 14. (a) Determination of the CIV by analytical methods; (b) comparison of our results obtained by analytical and numerical with numerical results reported in [35].

It could be observed that, at high strain rates, the integral leads to an asymptotic value close to $126 \mathrm{~m} / \mathrm{s}$. Since large plastic strain rates arise behind the plastic wave front when $V_{0}$ reaches the CIV, the asymptotic value could be taken as the prediction of the CIV using this analytical approach. A relatively good agreement is found as the first approximation of the CIV, but the analytical solution does not allow for the CIV to be defined precisely since the superposition of the elastic and plastic waves is not taken into account. This is the same case for the local adiabatic heating. To estimate more precisely the value of CIV a numerical analysis has been applied allowing us to take into account all the processes of elastic and plastic wave propagation in adiabatic conditions. The coupling with temperature via the balance of energy allows us to obtain the upper limit of the integral $\left.\varepsilon_{\mathrm{m}}^{\mathrm{p}}(T)\right|_{\varepsilon} ^{\mathrm{p}}$. A comparison of the CIV results is shown in the following picture, Fig. 14(b), between present result and the results reported in [35]. The argument $\rho_{n}$, introduced in [35], is the ratio of the density to the constant $K\left(\sigma=K\left(\varepsilon^{\mathfrak{p}}\right)^{n}\right), \rho_{n} \quad \rho / K$.

To estimate more precisely the value of CIV a numerical analysis using finite elements has been applied, allowing all processes of elastic and plastic wave propagation in adiabatic conditions to be taken into account. In conclusion, in the analytical approach the CIV is found in the range $\left.\mathrm{CIV}\right|_{\text {mild steel }} \sim 126 \mathrm{~m} / \mathrm{s}$.

\section{Estimation of the CIV for mild steel ES by FE simulations}

As reported by Wood [22] from experimental results, the position of the necking changes along the specimen as a function of the impact velocity. Starting from the central point of the specimen for quasi-static conditions, the neck moves firstly to the left (opposite to the impacted end) as soon as the impact velocity increases and inertial effects become determinant. Before the neck localizes at the im- pacted end when the impact velocity reaches its critical value, the phenomenon of double-necking appears as a transition between both situations, Fig. 15(c). Similar observations were found after numerical simulation of the specimen S3 with $l_{0} \quad 40 \mathrm{~mm}$ : for strain rates varying from 450 to $800 \mathrm{~s}^{1}$, double necking appears in the same way it has been experimentally observed, Fig. 15(c). Fig. 15 shows different instants of the process of doublenecking development for an impact velocity of $19 \mathrm{~m} / \mathrm{s}$. Below or above this range, the instability point localizes on the left, Figs. 15(a) and (b) or on the right (Figs. 15(d) and (e)). The numerical simulations also allowed us to establish that the neck develops at the left end only when the stress (around twice the elastic wave stress due to the higher impedance of the clamping) equals the yield limit. If the elastic wave intensity is lower than half the yield stress or above the yield stress, necking will occur always at the impacted end in dynamic conditions. For materials with higher values of the yield stress, necking in dynamic conditions may start first at the impacted end, moving then to the opposite end and finally to the impacted end again as the pulling velocity increases; this leads to two doublenecking situations (Fig. 16).

Regarding the phenomenon of CIV, as expected, a trapping of plastic waves occurs near the impact end for $V_{0} \geqslant 100 \mathrm{~m} / \mathrm{s}$, Fig. 15. As discussed previously, this occurs for all specimen lengths studied [34]. In conclusion the CIV in tension is directly related to the behavior of material and not to the specimen geometry used during experiment. For the shorter specimen, $l_{0} \quad 10 \mathrm{~mm}$, the plastic front is able to propagate along the specimen, due to its reduced length, and can reach the opposite end. In this case a more homogeneous strain distribution is observed with another neck appearing in the middle of the specimen. Such a situation is possible when the numerical analysis is performed without a failure criterion. 

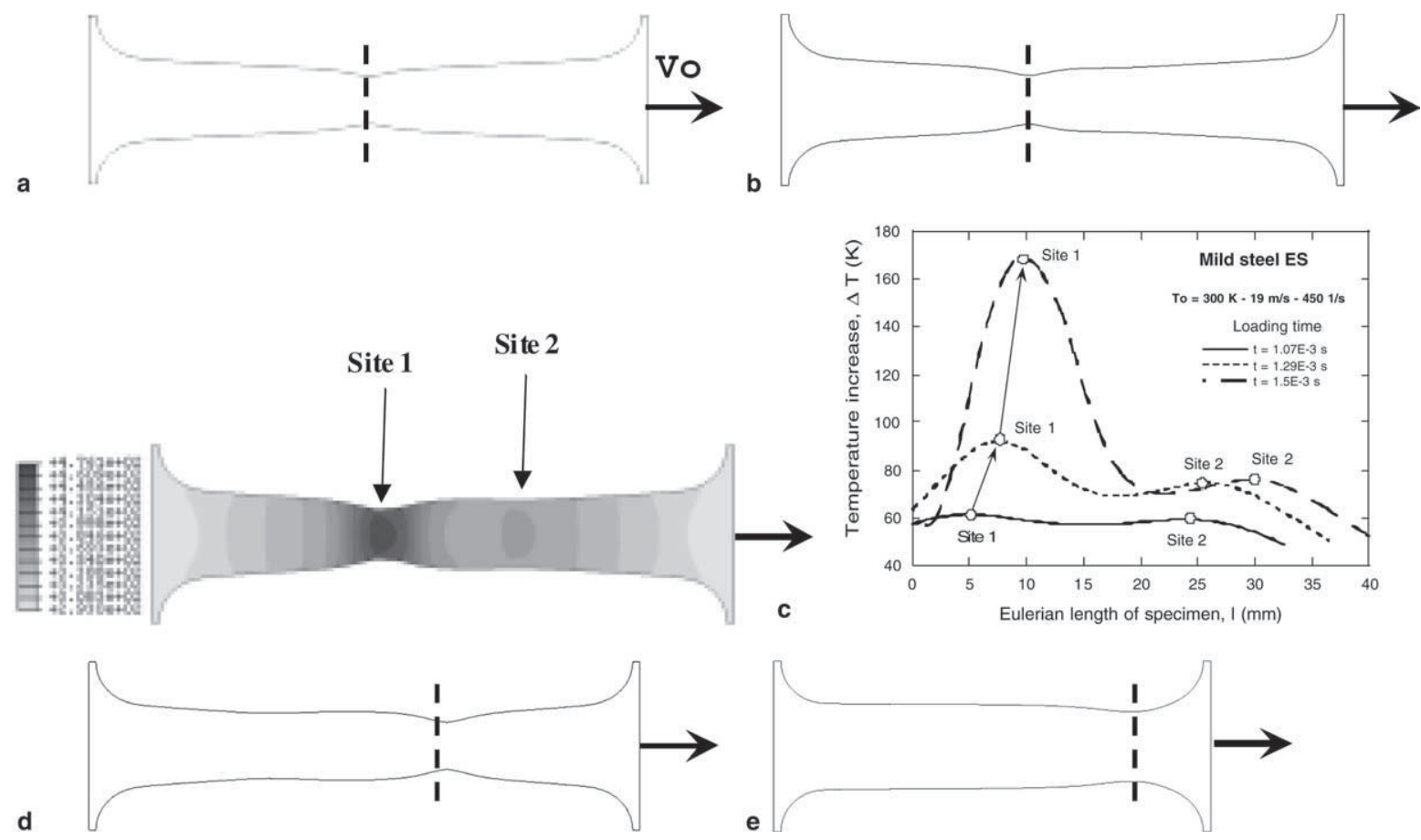

Fig. 15. Position of necking at different impact velocity $V_{0}$, initial length $l_{0}=40 \mathrm{~mm}$ : (a) $\dot{\bar{\varepsilon}}^{\mathrm{p}} \quad 100 \mathrm{~s}^{1} ;$; (b) $\dot{\bar{\varepsilon}}^{\mathrm{p}} \quad 200 \mathrm{~s}^{1} ;$ (c) $\dot{\bar{\varepsilon}}^{\mathrm{p}} \quad 450 \mathrm{~s}^{1} ;$ (d) $\dot{\bar{\varepsilon}}^{\mathrm{p}} \quad 800 \mathrm{~s}{ }^{1}$; (e) $\dot{\bar{\varepsilon}}^{\mathrm{p}} \quad 2500 \mathrm{~s}^{1}$

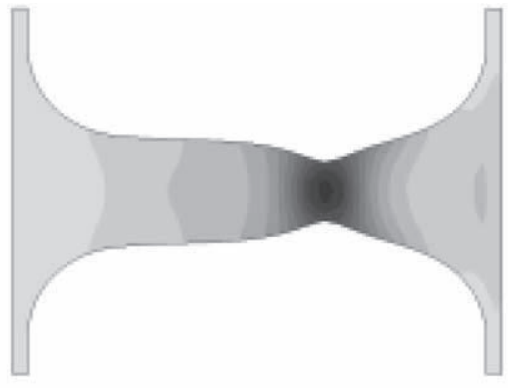

Geometry S1

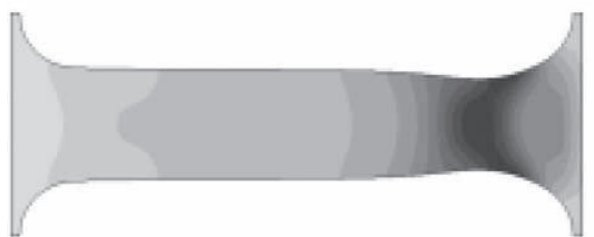

Geometry 33

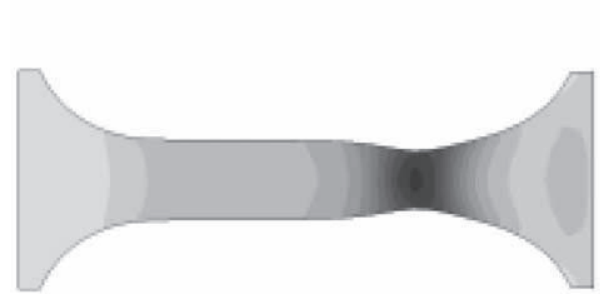

Geometry $A 0$

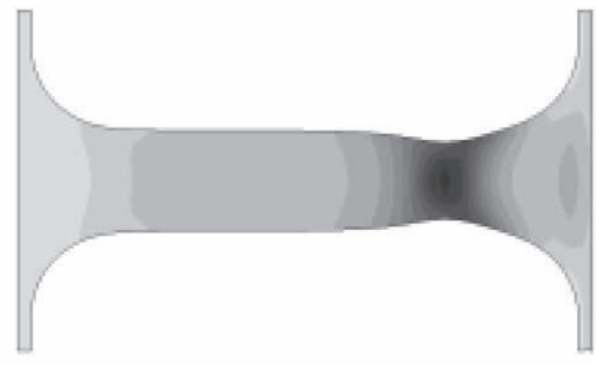

Geometry 52

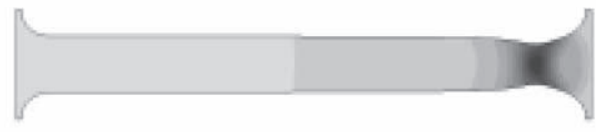

Geometry S4

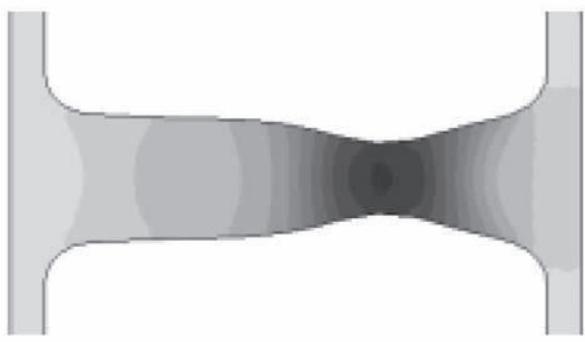

Geometry in [12]

Fig. 16. Approach of CIV for different geometries applied during numerical simulations, for every case $V_{0}=100 \mathrm{~m} / \mathrm{s}$. 


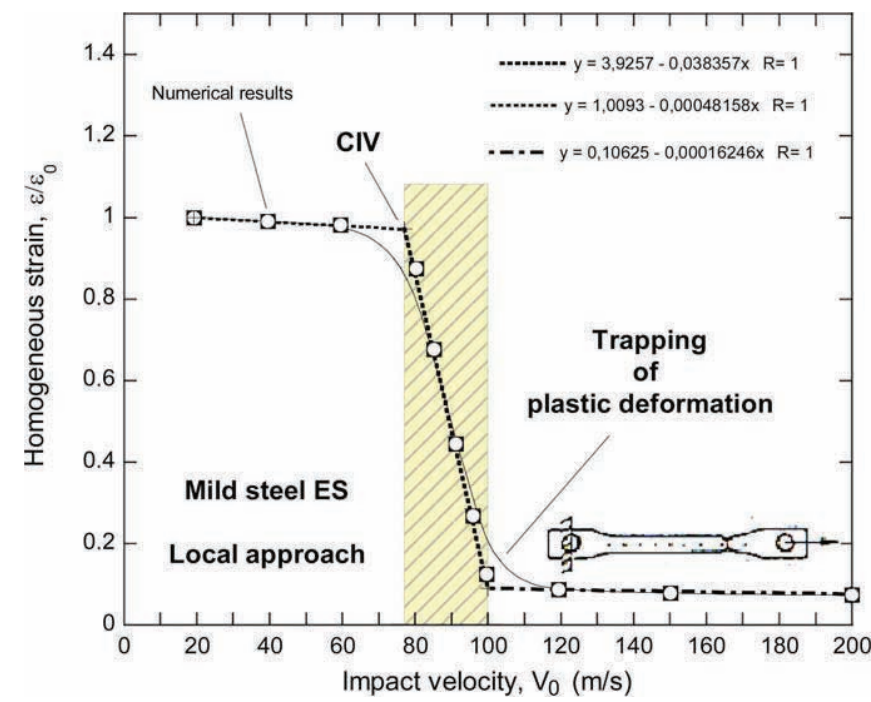

Fig. 17. Definition of the CIV by numerical simulation using relation between local and macroscopic approach.

A third approach for estimation of CIV is also proposed in this paper. In this case, a local analysis is applied using FE simulations. The general and complete approach was defined in [4]. The main idea is to analyze the local instability in the element where the necking takes place and to study the evolution of the local equivalent plastic strain $\varepsilon_{\text {local }}^{\mathrm{p}}$ in time. The second step is to determine in the same time the macroscopic level of plastic strain $\varepsilon_{\text {macro }}^{\mathrm{p}}$ corresponding to $\mathrm{d} F \quad 0$ or $\partial \sigma / \partial \varepsilon_{\text {macro }}^{\mathrm{p}}=\sigma$ (Considère criterion [43]). Plotting $\varepsilon_{\text {local }}^{\mathrm{p}}-\varepsilon_{\text {macro }}^{\mathrm{p}}$, it is possible to find the $\varepsilon_{\text {local }}^{\mathrm{p}}$ intensity at which the macroscopic homogeneity is lost. The normalized local plastic strain defined by this approach is plotted in Fig. 17, as a function of impact velocity $V_{0}$. In this case, the dynamic tension in adiabatic conditions has been analyzed. The observed transition is the same as reported in [34], Fig. 13(b), obtained by experiments. With this approach, the CIV limits can be estimated $80 \leqslant \mathrm{CIV} \leqslant 100 \mathrm{~m} / \mathrm{s}$, Fig. 17 .

It is necessary thus to take into account this new mechanical property in designing experiments. Its effect is important in the failure location but also for the problem of plastic wave propagation inducing for example two necking sites for long specimens.

\section{Conclusions}

The numerical simulations of the impact tension tests by FE code ABAQUS have enabled the demonstration of specimen behavior and the effect of initial specimen length during such a process of deformation for sheet metals. It was found that there is, as expected, a limiting value of the nominal strain rate, or impact velocity, for each specimen geometry below which the intrinsic material property can be determined. This threshold of the nominal strain rate is very important since above that value the material properties determined by impact tension become "apparent". Above that strain rate the shape of the "strain hardening curve" is affected by plastic wave propagation in adiabatic conditions. On the other hand, when an excessively short specimen is used the mean stress level determined is much higher in comparison to the true material behavior, due to the more intensified influence of the specimen ends [44].

The second point is the behavior of longer specimens during impact loading. In general, when the strain rate is not so high the deformation field along the specimen is more uniform than for short ones, but the maximum strain rate below which the results are correct diminishes. A more homogeneous distribution of plastic strain along a longer specimen in comparison with a shorter one is counterbalanced by a much lower strain rate for which the true material behavior can be correctly determined. The best geometry found for testing of sheet metals in impact tension is the $S_{2}$ one.

The numerical analyses of the adiabatic processes of plastic deformation coupled with plastic wave propagation in tension performed for several initial specimen lengths have revealed many interesting features. One of the purposes was to find an order of magnitude of the impact velocities above which the effect plastic waves is more important and leads to thermoviscoplastic instability and localization. For example, simulations of the tensile tests of sheet metals (ES steel and TA6V alloy $[23,24]$ ) have shown that below the impact velocity, $V_{0}<50 \mathrm{~m} / \mathrm{s}$, the distribution of longitudinal plastic strain is very similar on both sides of the short specimen $\left(l_{0} \quad 10 \mathrm{~mm}\right.$ ) but the force transmitted by such short specimens is much higher than expected from the intrinsic material behavior in one-dimensional stress. On the other hand, when the impact velocity is increased above $50 \mathrm{~m} / \mathrm{s}$, one observes from the beginning a loss of symmetry of the plastic field along the specimen (especially for long specimen). When the impact velocity reaches $100 \mathrm{~m} / \mathrm{s}$ necking occurs near the impact end, and the CIV in tension is reached. It is interesting to note that at relatively high impact velocities the form of the "strain hardening curve" and the stress level in reconstituted properties are affected by the initial length of specimen. It was also shown that the constitutive relation proposed some time ago $[1,4,20,40]$ allows the approximation of correctly thermoviscoplastic behavior of ES and TA6V sheet metals up to $10^{4} 1 / \mathrm{s}$.

\section{Acknowledgments}

The authors thank the Arcelor Research Group and more precisely Dr. D. Cornette and Dr. X. Lemoine for their interest and Dr. P. Larour from Aachen University (Germany) for Fig. 13(c).

\section{References}

[1] Rusinek A, Klepaczko JR. Etude numérique de la propagation des ondes dues à un chargement par impact. Rev Française Mécanique 2001;1:55 62 . 
[2] Rusinek A, Klepaczko JR. A double shear testing of a sheet steel at low and high strain rate in large deformation and a constitutive relation on the strain and temperature dependence of the flow stress. Int J Plast 2001;17:87 115.

[3] MacGregor C, Fisher JC. A velocity modified temperature for the plastic flow of metals. J Appl Mech 1946;13:11 6 .

[4] Rusinek A. Modélisation thermoviscoplastique d'une nuance de tôle d'acier aux grandes vitesses de déformation. Etude expérimentale et numérique du cisaillement, de la traction et de la perforation. $\mathrm{PhD}$ thesis, University of Metz; 2000.

[5] Symonds PS. Survey of methods of analysis for plastic deformation of structures under dynamic loading. Technical Report, Brown Univer sity; 1967.

[6] Johnson GR, Cook WH. Fracture characteristics of three metals subjected to various strains, strain rates, temperatures and pressures. J Eng Fract Mech 1985;21:31 48

[7] Zaho H. A constitutive model for metals over a large range of strain rates. Identification for mild steel and aluminium sheets. Mater Sci Eng A 1997;230:863 90

[8] Mourro P. Etude du comportement dynamique des tôles d'acier pour le calcul de crash. Thèse de l'Ecole Polytechnique de Paris; 2002.

[9] Zerrilli FJ, Armstrong RW. Dislocation mechanics based constitutive relations for materials dynamics calculations. J Appl Phys 1987;61:1816 25 .

[10] ABAQUS Explicit manual, Version 6.1. Hibbit, Karlson and Sorensen Inc., Providence (RI, USA).

[11] Clark DS, Duwez PE. The influence of strain rate on some tensile properties of steel. ASTM 1950:560 75.

[12] Tanimura S, Mimura K. Newly developed dynamic testing methods and dynamic strength of some structural materials. In: Akira Chiba, Tanimura S, Hokamoto K, editors. Proceeding of the 4th interna tional symposium on impact engineering, Kumamoto, Japan. Impact Eng Appl 2001;1:57 64.

[13] Yoshida F, Uemori T, Fujiwara K. Elastic plastic behavior of steel sheets under in plane cyclic tension compression at large strain. Int $\mathrm{J}$ Plast 2002;18:633 59.

[14] Stepanov G, Zubov V. Impact tensile tests of structural materials at high strain rates. In: Nowacki WK, Klepaczko JR, editors. New experimental methods in material dynamics and impact. War saw: IPPT PAN; 2001. p. 43743

[15] Klepaczko JR. True direct split Hopkinson bar for tension tests of sheet metals, ISGMP LPMM. Internal report for Sollac, Metz; 1995.

[16] von Karman Th, Duwez PE. On the propagation of plastic strain in solids. J Appl Phys 1950;21:987 93.

[17] Clark DS, Wood WW. The tensile impact properties of some metals and alloys. Proc ASTM 1950;42:45 52.

[18] Klepaczko JR. On critical impact velocities in tension and shear. Int J Impact Eng; 31 [in print].

[19] Klepaczko JR. Generalized conditions for stability in tension test. Int J Mech Sci 1968;10:297 313

[20] Rusinek A, Klepaczko JR. A numerical study on the wave propa gation in tensile and perforation test. J Phys IV 2000;10:653 8 .

[21] Duwez PE, Clark DS. An experimental study of the propagation of plastic deformation under conditions of longitudinal impact. ASTM 1947;42:45

[22] Wood WW. Experimental mechanics at velocity extremes very high strain rates. Exp Mech 1965;5:361 71.

[23] Chwalik P, Klepaczko JR, Rusinek A. Numerical analyses of the shear zone formation in impact shear test. Technical Meeting DYMAT; 2002.

[24] Lebouvier AS, Klepaczko JR. Numerical study of shear deformation in $\mathrm{Ti} 6 \mathrm{Al} 4 \mathrm{~V}$ at medium and high strain rates, critical impact velocity in shear. Int J Impact Eng 2002;27:755 69.
[25] Staab GH, Gilat A. A direct tension split Hopkinson bar for high strain rate testing. Exp Mech 1991;X:232 5.

[26] Nicholas T. Tensile testing of materials at high strain rates of strain. Exp Mech 1981;X:177 85

[27] Lindholm US, Yeakley LM. High strain rate testing: tension and compression. Exp Mech 1968;8:1 9.

[28] Stull DR, Shink GC. Thermodynamic properties of elements. Amer ican Chemical Society; 1956.

[29] N. Mouad, Etude expérimentale et modélisation du comportement viscoplastique de l'acier $316 \mathrm{LN}$ aux grandes déformations et vitesses de déformation; simulation numérique du cisaillement adiabatique. Thesis, University of Metz; 1999.

[30] Quinney H, Taylor GI. The emission of latent energy due to previous cold working when a metal is heated. Proc $\mathrm{R}$ Soc Lond 1937; $163: 15781$.

[31] Harding J, Wood EO, Campbell JD. Tensile testing of materials at impact rates of strain. J Mech Eng Sci 1960;2:88 96.

[32] Wang CY, Xia YM. Validity of one dimensional experimental principle for flat specimen in bar bar tensile impact apparatus. Int $\mathbf{J}$ Solids Struct 2000;37:3305 22.

[33] Rusty Gray III GT. Classical split Hopkinson pressure bar testing. ASM Handbook 2000;8:462 76

[34] Clark DS, Wood DS. The influence of specimen dimension and shape on the results in tension impact testing. $\mathrm{T}$ Am Soc Mech Eng 1957:577 85 .

[35] Hu X, Daehn GS. Effect of velocity on flow localization in tension. Acta Mater 1996;44:1021 33.

[36] Pond RB, Glass CM. Crystallographic aspects of high velocity deformation of aluminium single crystals. Interf Sci 1961;5:145 61 .

[37] Huh H, Kang WJ, Han SS. A tension split Hopkinson bar for investigating the dynamic behavior of sheet metals. Exp Mech 2002;42:8 17

[38] Albertini C, Montagnani M. Testing techniques based on the split Hopkinson bar. Inst Phys Conf Ser 1974(21):22 32.

[39] Zaera R, Fernandez Saez J. An implicit consistent algorithm for the integration of thermoviscoplastic constitutive equations in adiabatic conditions and finite deformation. Int J Solids Struct [accepted].

[40] Rusinek A, Zaera R, Klepaczko JR. Material characterization of a mild steel and constitutive relation for a wide range of strain rate and temperatures for 3D numerical simulations. Int $\mathbf{J}$ Mech Sci [submitted].

[41] Rusinek A, Zaera R. Finite element simulation of steel ring fragmentation under radial expansion. Int J Impact Eng [submitted].

[42] Faciu C, Molinari A. On modelling the longitudinal impact of two shape memory bars. In: 21th ICTAM congress proceeding. Warsaw, Poland; 2004.

[43] Considère AG. L'emploi du fer de l'acier dans les constructions Mémoire no. 34, Annales des Ponts et Chaussées, Paris; 1885. p. 574

[44] Rusinek A, Klepaczko JR. Numerical analysis of size effects and plastic wave propagation in impact tension tests. In: Proceedings of the VII national congress on mechanics, Hano1, Vietnam; 2002. p. 1 16.

[45] Dhulst ChA, Even D. Principe d'équivalence temps température: application de la théorie de l'activation thermique aux aciers. Evolution de la loi plastique avec la vitesse de déformation et la température. Rapport de Maîtrise, Université de Metz avec ARCE LOR; 2003.

[46] Klepaczko JR, Duffy J. Strain rate history effects in Body Centered Cubic metals, STP, vol. 765. West Conshohocken (PA): ASTM 1982. p. 25168.

[47] Tanimura S, Mimura K, Zhu W. A dynamic constitutive equation and its experimental verification. J Phys IV, Colloque C3 $2000 ; 10: 338$ 